\title{
IV SYMPOSIUM INTERNATIONAL D'ETUDES MORISQUES
}

Por

LUIS FERNANDO BERNABÉ PONS

Del 15 al 19 de marzo de 1989 tuvo lugar en Túnez el IV Congreso Internacional de Estudios Moriscos organizado por el Centre d'Etudes et de Rechercher OttomanesMorisques de Documentation et d'Information (CEROMDI), dirigido por el profesor Abdeljelil Temimi.

El apretado programa del Congreso se inició con la inauguración en un solemne acto de la Biblioteca del CEROMDI y la presentación del plan de las futuras instalaciones, todo ello en la ciudad de Zaghouan. En el acto intervinieron el Ministro de Cultura en Túnez, el profesor Habib Boulares; el Gobernador de Zaghouan, Sr. Daoud Ma'yiz; el Dr. Mikel de Epalza, de la Universidad de Alicante y el Prof. Temimi, como fundador y director del CEROMDI.

Por la tarde dieron comienzo las sesiones científicas en Túnez. En ellas los congresistas, venidos de diversas partes de África, América y Europa, desarrollaron con sus intervenciones los temas propuestos para el presente congreso:

- Los oficios de los moriscos.

- La vida religiosa de los moricos.

- La problemática occidental y árabo-musulmana de la historia morisca.

Debido al gran número de ponencias presentadas, todos los días fueron densos en intervenciones y coloquios. En ellos se volvió a incidir en temas que continúan siendo del máximo interés en el campo morisco. Así, hubo numerosas intervenciones en torno a la literatura aljamiado-morisca a cargo de especialistas del tema (A. GALMÉS DE FUENTES, A. VESPERTINO, O. HEGYI...), que profundizaron sobre diversos temas todavía no muy bien conocidos en este campo; la relación de estos moriscos con la literatura española (M. ${ }^{a}$ T. NARVÁEZ, F. ZMANTAR ...); las vicisitudes y huellas de los moriscos en sus países de emigración (A. TEMIMI, J. CHEIKHA, 
$\mathrm{CH}$. DE LA VERONNE...); las particularidades de su vivencia religiosa (C. LOPEZ MORILLAS, G. WIEGERS...); los diversos oficios por ellos desempeñados (M. BIRRIEL, A. GAFSI, A. SAADAOUI...).

Durante la celebración del Congreso, la embajada de España en Túnez y el Centro Cultural Español ofrecieron un homenaje al profesor Álvaro Galmés de Fuentes, cuya figura fue glosada por el Sr. embajador de España en Túnez y por el prof. Antonio Vespertino, de la Universidad de Oviedo. El Dr. Galmés de Fuentes pronunció una conferencia sobre la influencia de la literatura árabe en las literaturas románicas.

Por parte de la División Departamental de Estudios Árabes e Islámicos de la Universidad de Alicante participaron el Dr. Míkel de Epalza, vicepresidente del Comité Internacional de Estudios Moriscos, que presidió varias sesiones cientificas, y Luis F. Bernabé Pons, que presentó, junto con José J. Martínez, una comunicación sobre el problema religioso en el estado de lengua de los manuscritos moriscos. 